\title{
Process Optimization for Development of a Novel Water Kefir Drink with High Antioxidant Activity and Potential Probiotic Properties from Russian Olive Fruit (Elaeagnus angustifolia)
}

Darvishzadeh, Pariya; Orsat, Valérie; Martinez, José Luis

Published in:

Food and Bioprocess Technology

Link to article, DOI:

10.1007/s11947-020-02563-1

Publication date:

2021

Document Version

Peer reviewed version

Link back to DTU Orbit

Citation (APA):

Darvishzadeh, P., Orsat, V., \& Martinez, J. L. (2021). Process Optimization for Development of a Novel Water Kefir Drink with High Antioxidant Activity and Potential Probiotic Properties from Russian Olive Fruit (Elaeagnus angustifolia). Food and Bioprocess Technology, 14, 248-260. https://doi.org/10.1007/s11947-020-02563-1

\section{General rights}

Copyright and moral rights for the publications made accessible in the public portal are retained by the authors and/or other copyright owners and it is a condition of accessing publications that users recognise and abide by the legal requirements associated with these rights.

- Users may download and print one copy of any publication from the public portal for the purpose of private study or research.

- You may not further distribute the material or use it for any profit-making activity or commercial gain

- You may freely distribute the URL identifying the publication in the public portal 


\section{Process optimization for development of a novel water kefir drink with high antioxidant activity and potential probiotic properties from Russian olive fruit (Elaeagnus angustifolia)}

Pariya Darvishzadeh ${ }^{1 *}$, Valérie Orsat ${ }^{1}$ and José Luis Martinez ${ }^{2}$

${ }^{1}$ Department of Bioresource Engineering, McGill University, Montreal, Quebec, Canada

${ }^{2}$ Department of Biotechnology and Biomedicine, Technical University of Denmark (DTU), Lyngby, Denmark

*Corresponding author: Pariya Darvishzadeh

Email: Pariya.Darvishzadehboroojeni@ mail.mcgill.ca 


\section{Abstract}

Kefir is a dairy-based probiotic beverage with high antioxidant activity, among other health benefits. To extend kefir's beneficial health effects to non-dairy consumers, studies on kefir fermentation using alternative matrices (referred to as water kefir) are needed. As such, the purpose of this study was to formulate a novel water kefir beverage using Russian olive, as a non-dairy product with high antioxidant activity and potential probiotic properties. To this end, the Russian olive kefir water (RWK) fermentation process was optimized to maximize the total phenolic content, antioxidant activity, and microbial viability of this product. The experimental design was set using a rotatable central composite design with response surface methodology (RSM). The optimized independent variables included: the substrate concentration (20-30\% of Russian olive juice), fermentation time (24-48 h), and incubation temperature $\left(20-32^{\circ} \mathrm{C}\right)$. The optimal fermentation conditions were observed to be $31.2^{\circ} \mathrm{C}$ incubation temperature, 24 hours incubation time, and $30 \%$ Russian olive juice concentration. Under these conditions, the values for FRAP antioxidant activity, DPPH radical scavenging, and TPC in RWK were 0.22 ( $\mu \mathrm{mol} \mathrm{FSHE} / \mathrm{mL}), 0.096(\mu \mathrm{mol}$ Trolox Eq/mL) and $98.32(\mu \mathrm{g} \mathrm{GAE} / \mathrm{mL})$, and the microbial viability (of $\mathrm{AAB}, \mathrm{LAB}$, and yeasts) was 7.20, 7.06, and $7.17 \log 10 \mathrm{CFU} / \mathrm{mL}$, respectively.

Keywords: Russian olive water kefir, Fermentation, Antioxidant activity, Probiotic 


\section{Introduction}

The use of lactic acid bacteria as the primary agent for the production of fermented dairy products has a long history worldwide (Bitaraf et al. 2012; Zare et al. 2013; Fonteles et al. 2013; Nguyen et al. 2014). Alternatively, kefir grains, consisting of a symbiotic culture of lactic acid bacteria (LAB), yeast species, and acetic acid bacteria $(\mathrm{AAB})$, can be used as starter cultures for the fermentation of dairy matrices, resulting in a viscous pourable liquid product called kefir. In comparison with traditional fermentation processes, where single-species are used as a starter culture, kefir grains can be adapted to a variety of substrates due to their wide microbial diversity (Fiorda et al. 2017). The main alternative non-dairy substrate for kefir fermentation is sugar, which renders a beverage called water kefir (Marsh et al. 2013). Production of the water kefir is induced by mucilaginous and translucent water kefir grains, which have a polysaccharide matrix backbone (Pidoux 1989; Neve and Heller 2002). In fact, they contain a water-soluble matrix of dextran, a glucose polymer, which can retain the water during the process of fermentation and is firmly embedding the containing microbiota, whereas, in milk kefir, a glucogalactan, which is synthesized mainly by Lactobacillus kefiranofaciens holds the starter culture community of kefir (Gulitz et al. 2011; Martínez-Torres et al. 2017). In contrast with milk kefir grains, which employ milk as the substrate for fermentation, water kefir grains use sucrose as the substrate. However, in both products, the microbial communities include yeast, lactic acid bacteria, and acetic acid bacteria, each having different compositions and relative abundance (Martínez-Torres et al. 2017).

Traditionally water kefir is produced by fermentation of $8 \%$ sucrose solution containing dried fruits, some lemon slices, and the water kefir grains kept for 1-2 days at room temperature. As a result of such a fermentation process, a low acid carbonated drink is produced, yellowish, and

slightly alcoholic (Gulitz et al. 2011). Kefir and water kefir contain a variety of functional 
substances providing health benefits such as antioxidant, anti-hyperglycemic, anti-hyperlipidemic, anti-inflammatory, anti-ulcerogenic, and antimicrobial activities (Rodrigues et al. 2005, 2016; Alsayadi et al. 2013; Alsayadi et al. 2014). Water kefir grains contain LAB (including Lactobacillus paracasei, Lactobacillus parabuchneri, Lactobacillus kefiri, Lactobacillus Casei, and Lactococcus. lactis), AAB (including Acetobacter lovaniensis), and yeasts (including Saccharomyces cerevisiae), and various studies have shown the potential probiotic features of some of these water kefir grains associated microorganisms for application in the development of functional foods. In some water kefir microorganisms, these probiotic features include the capacity for antagonistic activity against potential pathogenic strains, adherence to epithelial cells, resistance to simulated gastric juice and bile salts, surviving transit through the gastrointestinal tract, and the potential for inducing activation of the gut mucosal immune system (Magalhães et al. 2010; Schneedorf 2012; Laureys and De Vuyst 2014; Diosma et al. 2014; Zanirati et al. 2015; Romero-Luna et al. 2020).

The ability of water kefir fermentation to improve the phenolic content profile of a product is mainly attributed to the action of microbial enzymes, which are produced over fermentation, cause degradation of the cell wall structure and subsequent release of bond phenolics. In addition, microbial metabolism of phenolic compounds through a variety of bioconversion pathways, such as glycosylation, deglycosylation, ring cleavage, methylation, glucuronidation, and sulfate conjugation, releases a broad range of new metabolisms (Huynh, Camp, Huynh, Smagghe, \& Raes, 2014). For example, lactic acid bacteria in the water kefir grains can contribute to the depolymerization of high molecular weight phenolic compounds (Hur et al. 2014). Hole, Rud et al. (2012) reported an increased release of phenolic acids and flavanols and a significant increase of ferulic acid and p-coumaric acid during fermentation of barely with some LAB strains. Studies 
have also indicated the scavenging activity of LAB against reactive oxygen species, and water kefir grains contain some of these species (Fiorda et al. 2016). In addition to LAB strains, different yeasts, such as Saccharomyces cerevisiae, available in water kefir grains, are proved to improve the wheat bran's free phenolic profile (Moore et al. 2007). On the other hand, various studies reported decreased total phenolic content and antioxidant activity during water kefir fermentation of fruits and vegetables (Corona et al. 2016; Randazzo et al. 2016). Therefore, the final water kefir product's total phenolic content and antioxidant activities are a balance between degradation and synthesis. Moreover, fermentation is desirable for improving the developed product's antioxidant profile because the bio-availability and bio-accessibility of a variety of compounds, including antioxidant compounds such as polyphenols and vitamins, are improved by the activity of a series of different enzymes. In fact, modification of the molecular nature of phenolic compounds during the fermentation process releases new derived compounds with the potential of biological activities such as changing the level of gut immunoglobin and populations of the microbiota. Improved bioavailability of polyphenols during fermentation improves their potential for in situ radical scavenging and enhances natural antioxidant body defenses (Septembre-Malaterre et al. 2018). In addition to changes in bioactive compounds, degradation of anti-nutritional factors, increase of nutrient density and secondary metabolites, short-chain fatty acids, and vitamins generated by the water kefir fermentation process result in improving health-related properties of the product.

To date, research has mainly focused on milk substrates to produce kefir as an excellent source of probiotics (Athanasiadis et al. 2004; Varga et al. 2006; Ghasemlou et al. 2012; Melo and Silva 2014; M'hir et al. 2019). To provide kefir's beneficial health effects to non-dairy consumers, a diversification in alternative non-dairy substrates used for kefir production is necessary. Adaptation of kefir grain with a variety of other non-dairy sources, including fruits and vegetables, 
has been tested for production of water kefir products as new functional beverages (Puerari et al. 2012; Baú et al. 2013; Cui et al. 2013; Corona et al. 2016; Fiorda et al. 2016; F. Fiorda et al. 2016; Randazzo et al. 2016; Rodrigues et al. 2016; Koh et al. 2017; Du and Myracle 2018; Łopusiewicz et al. 2019); however, currently, there is no reported study on the development of non-dairy kefir based on Russian olive fruit (Elaeagnus angustifolia). Extracts from fruits of Russian olive are rich in phytochemicals with high antioxidant properties (Wang et al. 2013; Incilay 2014; Farzaei et al. 2015). Investigation of the considerable antioxidant activity of Russian olive by other authors and our preliminary tests confirms the potential of this plant to be used as a valuable food ingredient, including in fermentation processes for producing beneficial fermented products. However, despite its excellent nutritional value and health benefits, Russian olive has not been widely used in the food sector (Farzaei et al. 2015). Moreover, there are numerous bioactivities associated with the consumption of kefir beverages, among which Russian olive shares many, including antioxidant, anti-inflammatory, anti-ulcerogenic, and antimicrobial activities (Rodrigues et al. 2005, 2016; Alsayadi et al. 2013; Alsayadi et al. 2014; Farzaei et al. 2015). Therefore, in this study, water kefir production using Russian olive develops a unique product, in which particular health benefits of water kefir can be enhanced.

Moreover, a standardized industrial process for water kefir production is not presently established, and this beverage is mostly produced at home or on a small-scale. Production of water kefir is based on a symbiotic relationship among the kefir microbial community. Different factors can affect their metabolic activities and, in turn, the quality of the produced kefir. These factors include the type of substrate and its ratio to the water kefir grains, incubation time, and temperature (Randazzo et al. 2016). Given the importance of antioxidant and probiotic activities among water kefir properties, the aim of this study is to develop and optimize the fermentation process with 
respect to both these activities in the beverage. Accordingly, the effects of fermentation factors such as time, temperature, and substrate concentration on total phenolic content (TPC), antioxidant activity, and viability of microorganisms of RWK was investigated. In addition, characteristics of the optimized water kefir beverage, including total soluble solids Brix $\left({ }^{\circ} \mathrm{Br}\right), \mathrm{pH}$, viscosity, and ethanol content, were assessed. In our study, the use of Russian olive juice as the main substrate in the formulation of a water kefir beverage is proposed.

\section{Materials and Methods}

\subsection{Experimental design}

The experimental design, regression analysis of the data, and model building were performed using the software Design-Expert (version 10.0.7.0, Stat-Ease Inc., Minneapolis, USA). The experiments were developed with three factors using a rotatable Central Composite Design (CCD), including the central point (five replicates). Factors included concentration of Russian olive (20, 25 , or $30 \%)$, fermentation duration $(24,36$ or $48 \mathrm{~h})$, and temperature $\left(20,26\right.$, or $\left.32^{\circ} \mathrm{C}\right)$, each at three coded levels $-1,0,1$. Twenty experiments in duplicates were conducted for optimization of the RWK fermentation process (Table 1). 
Table 1 Matrix of the central composite design (CCD) and observed responses (Yj) for different experimental conditions (mean values of three replicates).

\begin{tabular}{|c|c|c|c|c|c|c|c|c|c|}
\hline Run & & Independe & t variables & Response variables & & & & & \\
\hline & $\begin{array}{l}\text { Time } \\
\left(\mathrm{x}_{1}, \mathrm{~h}\right)\end{array}$ & $\begin{array}{l}\text { Temperature } \\
\left(x_{2},{ }^{\circ} \mathrm{C}\right) \\
\end{array}$ & $\begin{array}{l}\text { Russian olive juice } \\
\left(x_{3}, \% \mathrm{v} / \mathrm{v}\right)\end{array}$ & 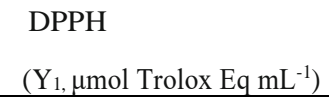 & $\begin{array}{l}\text { FRAP } \\
\left(\mathrm{Y}_{2}, \mu \mathrm{mol} \text { FSHE } \mathrm{mL}^{-1}\right)\end{array}$ & $\begin{array}{l}\text { TPC } \\
\left(\mathrm{Y}_{3,\left(\mu \mathrm{g} \mathrm{GAE} \mathrm{mL}^{-1}\right)}\right.\end{array}$ & $\begin{array}{l}\text { AAB viability } \\
\left(\mathrm{Y}_{4}, \log _{10} \mathrm{CFU} \mathrm{mL}^{-1}\right)\end{array}$ & $\begin{array}{l}\text { Yeast viability } \\
\left(\mathrm{Y}_{5} \log _{10} \mathrm{CFU} \mathrm{mL} \mathrm{mL}^{-1}\right)\end{array}$ & $\begin{array}{l}\text { LAB viability } \\
\left(\mathrm{Y}_{6,} \log _{10} \mathrm{CFU} \mathrm{mL} \mathrm{mL}^{-1}\right)\end{array}$ \\
\hline 1 & 24.00 & 20.00 & 20.00 & 0.090 & 0.124 & 68.803 & 6.070 & 5.977 & 6.875 \\
\hline 2 & 24.00 & 32.00 & 20.00 & 0.097 & 0.152 & 56.205 & 7.197 & 7.050 & 7.105 \\
\hline 3 & 24.00 & 20.00 & 30.00 & 0.129 & 0.175 & 113.51 & 6.740 & 6.633 & 6.903 \\
\hline 4 & 24.00 & 32.00 & 30.00 & 0.124 & 0.197 & 100.765 & 7.249 & 7.075 & 7.130 \\
\hline 5 & 24.00 & 26.00 & 25.00 & 0.111 & 0.148 & 89.931 & 7.431 & 7.027 & 7.161 \\
\hline 6 & 36.00 & 20.00 & 25.00 & 0.068 & 0.154 & 68.411 & 6.583 & 6.201 & 7.017 \\
\hline 7 & 36.00 & 26.00 & 20.00 & 0.064 & 0.142 & 67.215 & 7.124 & 6.844 & 7.208 \\
\hline 8 & 36.00 & 26.00 & 25.00 & 0.073 & 0.185 & 86.5 & 7.163 & 6.580 & 7.269 \\
\hline 9 & 36.00 & 26.00 & 25.00 & 0.102 & 0.168 & 83.411 & 7.111 & 6.538 & 7.054 \\
\hline 10 & 36.00 & 26.00 & 30.00 & 0.084 & 0.168 & 99.147 & 7.293 & 6.646 & 7.278 \\
\hline 11 & 36.00 & 26.00 & 25.00 & 0.073 & 0.130 & 59.637 & 7.547 & 7.082 & 7.153 \\
\hline 12 & 36.00 & 26.00 & 25.00 & 0.030 & 0.113 & 60.215 & 7.392 & 6.830 & 7.166 \\
\hline 13 & 36.00 & 26.00 & 25.00 & 0.083 & 0.129 & 55.470 & 7.369 & 6.960 & 7.236 \\
\hline 14 & 36.00 & 32.00 & 25.00 & 0.083 & 0.160 & 74.539 & 7.288 & 7.019 & 7.140 \\
\hline 15 & 36.00 & 26.00 & 25.00 & 0.080 & 0.115 & 56.254 & 7.353 & 6.752 & 7.208 \\
\hline 16 & 48.00 & 26.00 & 25.00 & 0.069 & 0.157 & 69.637 & 7.361 & 6.216 & 7.021 \\
\hline 17 & 48.00 & 32.00 & 20.00 & 0.017 & 0.110 & 46.107 & 7.432 & 6.720 & 7.108 \\
\hline 18 & 48.00 & 32.00 & 30.00 & 0.040 & 0.225 & 85.176 & 7.217 & 6.907 & 7.153 \\
\hline 19 & 48.00 & 20.00 & 20.00 & 0.045 & 0.081 & 48.411 & 7.021 & 6.120 & 6.645 \\
\hline 20 & 48.00 & 20.00 & 30.00 & 0.051 & 0.163 & 88.362 & 7.047 & 6.447 & 7.243 \\
\hline
\end{tabular}




\subsection{Preparation of water kefir grains and fermentative medium}

Field-grown fruits of Russian olive were harvested from a local farm in Iran and Water kefir grains which contain LAB (including Lactobacillus paracasei, Lactobacillus parabuchneri, Lactobacillus kefiri, Lactobacillus Casei, and Lactococcus. lactis), AAB (including Acetobacter lovaniensis) and yeasts (including Saccharomyces cerevisiae) were provided by the Happy Kombucha Company, Eastbourne, England. In order to eliminate the influences associated with the previous cultivation process of the supplier, grains $(50 \mathrm{~g} / \mathrm{L})$ were activated in 4 liters of sterilized sucrose solution (10\%, w/v) and incubated at room temperature for 24 hours (Magalhães

et al. 2010). Incubation was repeated three times before the grains were considered ready to be used. Sucrose solution was prepared by dissolving sucrose in deionized water and was sterilized through filtration using membrane filters with pore sizes of $0.22 \mu \mathrm{m}$. To prepare Russian olive juice for the experiments, pesticide-free Russian olive fruits were air-dried. Seeds were separated, and exocarp plus endocarp, with a moisture content of $11.8 \%$, were milled into powder in a blender. Fruit powder was extracted in deionized water by mixing $15.4 \mathrm{~g}$ Russian olive with $100 \mathrm{~mL}$ water. Following stirring for 30 minutes, the juice was separated through centrifugation for 10 minutes at $10,000 \mathrm{x}$ g. Prepared Russian olive fruit juice was pasteurized at $75^{\circ} \mathrm{C}$ for $5 \mathrm{~min}$ before use in the fermentation process.

\subsection{Preparation of RWK beverage and fermentation conditions}

Experiments were performed (2 biological replicates per condition) in 1.0 L Biostat Qplus bioreactors (Sartorius Stedim Biotech, Germany). The working volume in each fermenter vessel was $0.4 \mathrm{~L}$ containing 20 grams of water kefir grains ( $50 \mathrm{~g} / \mathrm{L})$, pasteurized Russian olive juice (20, 25 , or $30 \% \mathrm{v} / \mathrm{v}$, depending on experimental run), and 32 grams of sucrose (dissolved in a volume of deionized water equal to the remaining volume of each bioreactor to give a final concentration 
of $8 \% \mathrm{w} / \mathrm{v}$ of sucrose in a $0.4 \mathrm{~L}$ bioreactor). The prepared sucrose solutions were filter-sterilized before adding to each bioreactor. During the experiments, the temperature was maintained at 20, 26 , or $32^{\circ} \mathrm{C}$ and fermentation continued for 24,36 , or 48 hours (depending on each condition) while $\mathrm{pH}$ was monitored using $\mathrm{pH}$ sensors (Model EasyFerm Plus K8 160, Hamilton). Each bioreactor was equipped with an impeller, and stirring was constant at $100 \mathrm{rpm}$ to assure consistency between different runs. At the end of each experiment, samples were taken out from the water kefir liquor through a sampling tube using a syringe. Samples were analyzed in triplicates, and the results were expressed as mean values.

\subsection{Evaluation of the total phenolic content through the Folin-Ciocalteu assay}

For measuring the total phenolic content of the samples, the Folin-Ciocalteu assay was used using gallic acid as the standard following a method by Pientaweeratch et al. (2016) with slight modifications. Briefly, $20 \mu \mathrm{L}$ of each test sample was mixed with $80 \mu \mathrm{L}$ of sodium carbonate $(7.5 \%$ in deionized water) and $100 \mu \mathrm{L}$ of Folin-Ciocalteu reagent (diluted 10-fold in deionized water) in a 96-well plate. After 60 minutes of incubation at room temperature, the absorbance was measured at $765 \mathrm{~nm}$ using a microplate reader, and the results were expressed as $\mu \mathrm{g}$ gallic acid equivalent (GAE) /mL of sample.

\subsection{Determination of antioxidant activity}

The total antioxidant capacity of the samples was measured using 2 spectrophotometric assays, including 1,1-diphenyl-2-picrylhydrazyl (DPPH) method and ferric reducing antioxidant power (FRAP) assay (Brand-Williams et al. 1995; Benzie and Strain 1996). 


\subsubsection{Estimation of DPPH radical-scavenging capacity}

The antioxidant activities of the samples were determined using a modified DPPH assay introduced by Brand-Williams et al. (1995). Briefly, $250 \mu \mathrm{L}$ of prepared DPPH solution (0.2 mM) was added to $25 \mu \mathrm{L}$ of water kefir samples in a 96-well microplate. The mixtures were incubated for 30 minutes, and then absorbance was determined at $517 \mathrm{~nm}$ using a microplate reader. Finally, the results were expressed as $\mu \mathrm{mol}$ Trolox equivalent $/ \mathrm{mL}$ of sample.

\subsubsection{Determination of ferric reducing antioxidant power (FRAP)}

For measuring the antioxidant activity of the samples using the FRAP assay, a modified method introduced by Benzie and Strain (1996) was followed. Briefly, $250 \mu \mathrm{L}$ of the freshly made FRAP reagent was mixed with $25 \mu \mathrm{L}$ of water and $8.5 \mu \mathrm{L}$ of the samples in a 96-well microplate. After 30 minutes of incubation, the absorbance was read at $593 \mathrm{~nm}$ using a microplate reader. The results were expressed as $\mu \mathrm{mol} \mathrm{FeSO}_{4} .7 \mathrm{H}_{2} \mathrm{O}$ equivalent (FSHE)/mL of the sample.

\subsection{Determination of lactic acid bacteria, yeast, and acetic acid bacteria cell viability}

Samples were prepared according to the Association of Official Analytical Chemists' guidelines (AOAC 1990). Isolation of $\mathrm{LAB}, \mathrm{AAB}$, and yeasts in the samples was carried out by plating different dilutions on appropriate media following methods by ISO (1998), Gulitz (2013), Atalar and Dervisoglu (2015) and Hsieh et al. (2012) with slight modifications. Viable bacteria or yeasts in the samples were quantified using the drop plate method. Following sequential dilution stages, a serial dilution was prepared using a sterile saline solution $(0.85 \%$ sodium chloride solution, $\mathrm{pH}$ 7.2-7.4). Then, ten $\mu \mathrm{L}$ of each dilution was transferred to the appropriate agar plate for $\mathrm{LAB}$, $\mathrm{AAB}$, and yeasts. After the growth of colonies at optimum conditions, they were counted, and the number of bacteria/yeast in the original samples was calculated as colony-forming units per $\mathrm{mL}$ (CFU/mL). LAB count was performed on de Man, Rogosa and Sharpe (MRS) agar (pH 5.7), in 
which cycloheximide $(150 \mu \mathrm{g} / \mathrm{mL})$ was added to inhibit the growth of yeasts. The MRS agar plates were incubated for 72 hours at $30{ }^{\circ} \mathrm{C}$. AAB was enumerated on GM agar (pH 6.0) containing cycloheximide $(150 \mu \mathrm{g} / \mathrm{mL})$ to inhibit the growth of yeasts followed by incubation at $30{ }^{\circ} \mathrm{C}$ for 72 hours. For yeast isolates, YPG agar (pH 6.5) was used, in which chloramphenicol (100 mg/L) was added to inhibit bacterial growth and bromphenol blue $(0.01 \mathrm{~g} / \mathrm{L})$ was mixed for morphological differentiation following 3 days of incubation at room temperature.

\subsection{Characterization of optimized RWK beverage}

Samples of the optimized RWK beverage were subjected to several physicochemical characterizations following the standard methodologies described by AOAC (2000). The $\mathrm{pH}$ values were determined electrometrically using a pH probe (Mettler Toledo, Switzerland). Soluble solids content (SSC) was evaluated using a portable refractometer and reported as degree Brix $\left({ }^{\circ} \mathrm{Br}\right)$. Rheological properties of the sample were measured according to Nindo et al. (2005) with modifications and using a controlled stress rheometer (Discovery Hydrid Rheometer HR-3, TA Instruments, Delaware, USA). The instrument was equipped with a concentric cylinder geometry with a $30.33 \mathrm{~mm}$ cup, and a gap of $1 \mathrm{~mm}$ was employed. Before measurements were taken, five minutes was allowed for sample equilibration, and sample viscosity was determined by linearly increasing shear rate from 1 to 100 1/s at $25 \mathrm{C}$. The ethanol content of water Kefir samples was measured following Atalar and Dervisoglu (2015) method. Briefly, samples were filtered on a 0.45 $\mathrm{mm}$ membrane filter and injected into a gas chromatograph equipped with a flame-ionization detector. In addition, TPC and antioxidant activity of the optimized product were measured using previously discussed assays. 


\subsection{Statistical analysis}

Response surface methodology (RSM) was used to determine the effects of three experimental variables and their interactive relationship on the response variables. All responses were equally weighted, and using analysis of variance Fisher test value (ANOVA F-test), response variables were analyzed to identify the significant factors and accuracy of the suggested model. Subsequently, $\mathrm{P}$-value $(p \leq 0.05)$, as well as the coefficient of determination $\mathrm{R}^{2}$ and $\mathrm{R}^{2}$ adj, were used to express the quality of the fit of the polynomial model.

\subsection{Verification of the models}

When the Russian olive water kefir fermentation process's optimal conditions were determined, the fermentation process was conducted under these conditions to verify the models' validity by comparing the corresponding experimental values with model-predicted response values.

\section{Results and discussion}

\subsection{Effects of the experimental variables on total phenolic content (TPC) and antioxidant activities (FRAP and DPPH) of RWK}

Figure 1 illustrates the variation of TPC and antioxidant activity with Russian olive juice concentration, time, and temperature. The data obtained indicates that with the increase in Russian olive juice concentration, TPC and DPPH radical scavenging activity significantly $(p<0.01)$ increased, reaching the highest level at the concentration of $30 \%$ Russian olive juice. On the other hand, the values for TPC and DPPH of RWK decreased by increasing fermentation time and temperature (Table 2). It was observed that at time $24 \mathrm{~h}$ and a temperature of $20^{\circ} \mathrm{C}, \mathrm{TPC}$ and DPPH radical scavenging activity reach the highest level. At a higher temperature than $20^{\circ} \mathrm{C}$ and after 24 hours of fermentation, lower DPPH radical scavenging activity was observed. One possible explanation might be that at higher temperatures, close to the optimum temperature for microbial 
metabolic activities, the structure of phenolic compounds is influenced by the action of microbial enzymes converting them into other molecules, which in turn affects the antioxidant activity of the beverage (Ekbatan et al. 2016). Also, the stability of some of the natural phenols and antioxidant compounds is $\mathrm{pH}$-dependent; therefore content and structure of the phenolic compounds are influenced by changes in $\mathrm{pH}$ throughout the fermentation, which ultimately affects the total phenolic content and antioxidant activity of the product (Hur et al. 2014). However, there could be a certain level of improved antioxidant activities attributed to microbial-derived phenolic metabolites (Ekbatan et al. 2016). At first, water kefir fermentation can increase the total phenolic content and antioxidant activity by inducing the Russian olive cell wall's structural breakdown through hydrolysis by microbial enzymes, releasing various bioactive compounds inducing their synthesis. Moreover, Huynh et al. (2014) illustrated a summary of various metabolic pathways of phenolic compounds by microbial fermentation, among which there are particular metabolic pathways for the phenolic compounds and microorganisms, which are shared with Russian olive and water kefir grains, respectively. Therefore, in addition to microorganisms' action on releasing bound phenolic compounds from the plant cell walls, they can also convert phenolic compounds into more simplified metabolites for improving their bioactivities (Heim et al. 2002; Huynh et al. 2014). Subsequently, enhancement of the phenolic profile of Russian olive and its antioxidant properties over water kefir fermentation is anticipated.

Due to synergism between the polyphenolic compounds and other components in the fermentation, which contributes to the total antioxidative activity of the RWK, it cannot be predicted based on TPC alone. However, there is a correlation between TPC and antioxidant activity, particularly with the DPPH radical scavenging observed in this study. The conclusion is that an increase in TPC with higher Russian olive juice concentration and reduced fermentation time can increase the 
antioxidant activity (FRAP and DPPH radical scavenging activity) of RWK. Overall, our results showed that total phenolic content and antioxidant activity of RWK are decreased throughout the fermentation process (compared to the starting point of the fermentation process (time zero) with the values of $132.4 \mu \mathrm{g}$ GAE/mL, $0.35 \mu \mathrm{mol} \mathrm{FSHE} / \mathrm{mL}$, and $0.18 \mu \mathrm{mol}$ Trolox Eq/mL for TPC, FRAP antioxidant activity and DPPH radical scavenging activity, respectively). It can be explained by fermentative changes to the bioactive compounds, including phenolic compounds, which are converted to other molecules with varied biological activities. However, they remain significantly higher than the control water kefir sample produced using sucrose solution (with the values of 6.3 $\mu \mathrm{g}$ GAE/mL, $0.014 \mu \mathrm{mol}$ FSHE/mL, and $0.021 \mu \mathrm{mol}$ Trolox Eq/mL for TPC, FRAP antioxidant activity, and DPPH radical scavenging activity, respectively). In a similar study by Randazzo et al. (2016) on water kefir fermentation of different fruit juice, all fruit juices showed a decreased TPC (up to $53 \%$ decrease) and reduced DPPH antioxidant activity (up to 19\%) after water kefir fermentation. Corona et al. (2016) also reported up to $49 \%$ decrease in the total phenolic content of juice after water kefir fermentation. When sucrose is used as the only carbon source for water kefir production, Fiorda et al. (2016) and Alsayadi et al. (2013) indicated improvement in the total phenolic compound and antioxidant activity after fermentation. Similar observations of increased antioxidant activity were made in our control sample, in which sucrose was used as the only carbon source in the media for the water kefir fermentation process (increased level of $1.92 \mu \mathrm{g}$ GAE $/ \mathrm{mL}$, $0.009 \mu \mathrm{mol} \mathrm{FSHE} / \mathrm{mL}$, and $0.014 \mu \mathrm{mol}$ Trolox $\mathrm{Eq} / \mathrm{mL}$ for TPC, FRAP antioxidant activity and DPPH radical scavenging activity, respectively). In this study, when Russian olive and sucrose were combined as the source of carbon for fermentation, the total antioxidant activity of the RWK samples decreased after fermentation. However, despite the decrease in antioxidant activity, the results were significantly higher than for the water kefir samples fermented using sucrose alone. 
This is in accordance with our hypothesis; by replacing the standard sucrose solution or even part of it with Russian olive with high antioxidant activity, the antioxidant properties of the produced water kefir can be considerably increased compared to water kefir in which only sucrose is used as the substrate.

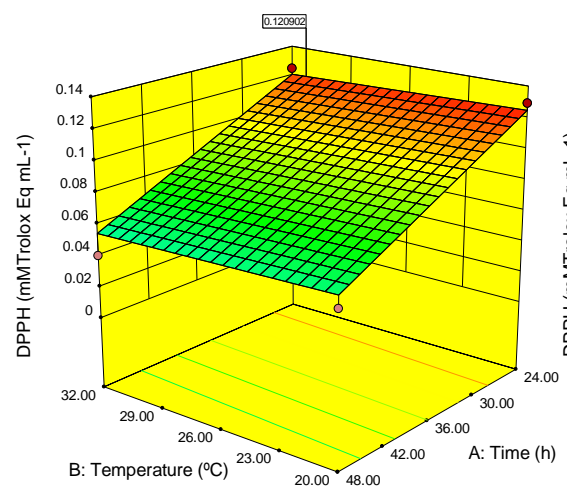

a

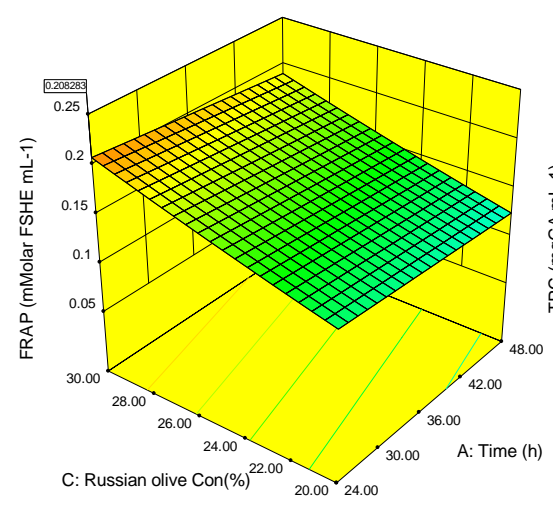

d

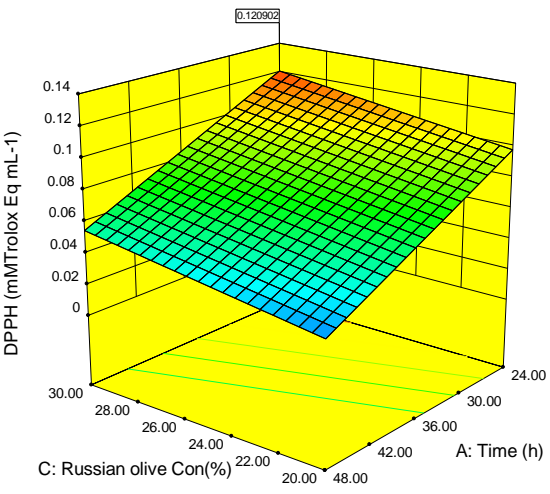

b

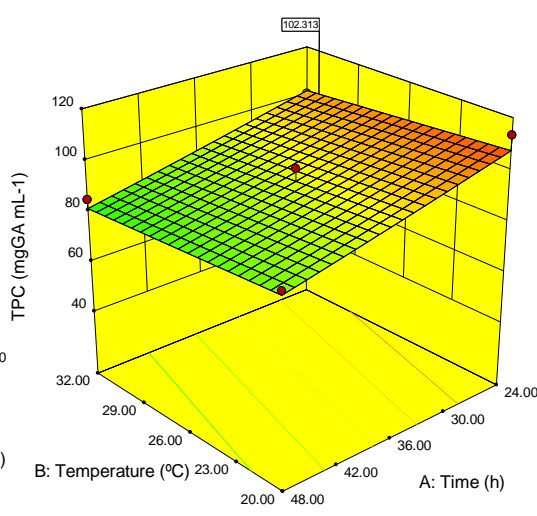

e

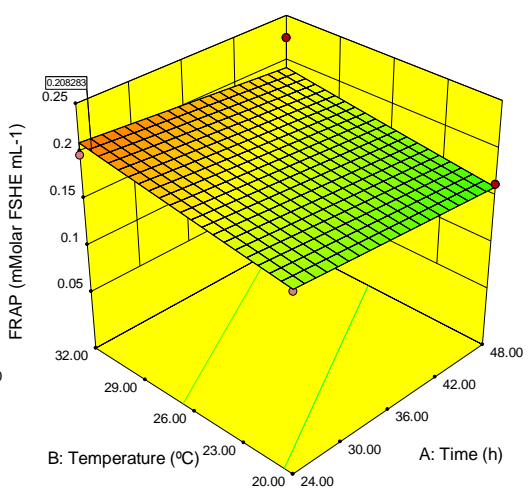

C

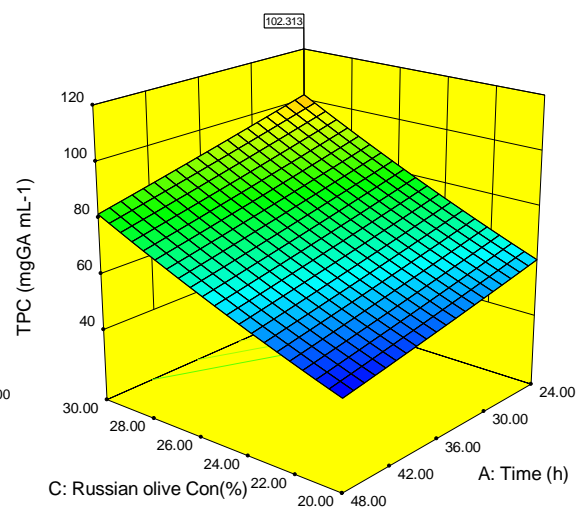

f

Figure $13 D$ plots showing the combined effect of time, temperature and Russian olive juice concentration on $(A-B) A A D P P H$ radical, (C-D) AAFRAP and (E-F) TPC.

\subsection{Effects of the experimental variables on $L A B, A A B$, and yeast cell viability of water kefir microorganisms in RWK}

Production of water kefir is based on a symbiotic relationship among the kefir microbes (including yeasts, $\mathrm{LAB}$ and $\mathrm{AAB})$. Different factors can affect their metabolic activities, among which the concentration of substrate, incubation time, and temperature were evaluated in this study. Despite some unique features, the results regarding the effect of independent experimental variables on 
$\mathrm{AAB}, \mathrm{LAB}$, and yeasts of RWK beverage showed a similar trend, including the positive effect of temperature and Russian olive juice concentration on cell viability of RWK microorganisms (Fig. 2). From the ANOVA of the response surface quadratic model, there were significant effects $(p<0.05)$ of the fermentation variables on the microbial proliferation of RWK microorganisms, producing first-order significant $(p<0.01)$ linear effect of temperature on $\mathrm{AAB}, \mathrm{LAB}$, and yeasts and significant interactive effects (Time $\times$ Temp) and (Time $\times$ Russian olive Con) on AAB and yeast respectively (Table 2). The number of viable cells of AAB and LAB was shown to be significantly $(p<0.05)$ affected by the time of fermentation; however, it showed to have no significant effect on the viability of yeast cells. (Figure $2 \mathrm{~B}, \mathrm{E}$, and $\mathrm{G}$ ). The highest number of cells for $\mathrm{AAB}$ and yeasts was shown to be at 47 and 36 hours of fermentation, whereas Figure 2 showed the highest number of cells for LAB at 27 hours of fermentation. Longer fermentation time for optimum growth and viability of $\mathrm{AAB}$ and yeasts compared to the $\mathrm{LAB}$ can be due to $\mathrm{AAB}$ and yeasts' symbiotic interaction during water kefir fermentation. The presence of ethanol, produced by the yeast cells, facilitates the growth of acetic acid bacteria. Acetic acid bacteria transform glucose to gluconic acid and fructose into acetic acid and, thereby, the increased production of acetic acid stimulates the yeast cells to convert sugar and produce ethanol via the glycolysis metabolic pathway (Ayed et al. 2017). Moreover, increased fermentation time was shown to positively affect AAB's proliferation but negatively affected the growth of the LAB and yeast cells. This can be due to the increased production of ethanol with increased fermentation time, which consequently facilitates the growth of acetic acid bacteria. During the kefir fermentation, other microbial interactions can exist; however, the mechanisms of symbiotic interaction of microorganisms of kefir grains are still not well known (Fiorda et al. 2017). The optimal proliferation of $\mathrm{AAB}, \mathrm{LAB}$, and yeasts was observed at 28,31 , and $26{ }^{\circ} \mathrm{C}$, respectively. 
Figure $2(\mathrm{~B}, \mathrm{E}$, and $\mathrm{G})$ presents a gradual linear increase in cell growth of $\mathrm{AAB}, \mathrm{LAB}$, and yeasts when the fermentation temperature increased to close to their optimum temperature for growth. The increase in $\mathrm{LAB}$ and $\mathrm{AAB}$ was more significant $(p<0.05)$ than for yeasts, as indicated by the highest coefficients in Table 2. This linear effect is confirmed as the concentration of Russian olive juice increased. Mishra and Mishra (2015) also reported free sugar and temperature as important factors for guaranteeing a sufficient number of viable probiotic cells in fermented products. An increase in $\mathrm{AAB}, \mathrm{LAB}$, and yeast cells upon the increasing concentration of Russian olive juice in RWK could be attributed to the increased availability in nutrients, which may sustain water kefir microorganisms' metabolic activities at the accumulation of higher concentration of organic acids. Consequently, the accessibility to essential nutrients, including carbon and nitrogen sources for the growth of bacteria and yeast, can maintain the high level of microbial proliferation.

Overall, the fermentation of water kefir is traditionally performed at room temperature. Commonly used incubation time and temperatures are recommended as $25^{\circ} \mathrm{C} / 24 \mathrm{~h}$ by Magalhães et al. (2010) and Marsh et al. (2013) and $21{ }^{\circ} \mathrm{C} / 24 \mathrm{~h}$ by Alsayadi et al. (2013). However, for the growth of mesophilic bacteria and yeasts present in the water kefir grains, $32{ }^{\circ} \mathrm{C}$ is reported as the optimum temperature by Koh et al. (2017). The results of our study indicate 24 hours of fermentation at $31.2^{\circ} \mathrm{C}$ as the optimized conditions for the maximum level of cell growth. This aligns with the most relevant study by Koh et al. (2017), who reported $24 \mathrm{~h}$ at $32{ }^{\circ} \mathrm{C}$ as the optimal conditions for the fermentation of pumpkin water kefir with good overall acceptability and higher microbial proliferation. According to the Canadian Food Inspection Agency (2019) and Codex Alimentarius Commission (2018), in order to exert a beneficial health impact, the recommended number of viable cells in fermented food products is $1.0 \times 10^{9} \mathrm{CFU}$ of one or more of the eligible 
probiotic microorganism(s) per serving size of a product. On the other hand, according to Bertazzoni et al. (2013), the volume of the consumed probiotic drink is often 100-200 mL. According to Table 4, the number of viable cells of $\mathrm{AAB}, \mathrm{LAB}$, and yeasts in the optimized RWK is $7.20,7.06$, and $7.17 \log _{10} \mathrm{CFU} / \mathrm{mL}$, respectively. Therefore, a minimum number of $10^{9}$ live probiotics per 100-200 mL serving size of RWK is expected to be reached and shows that the optimized RWK can potentially deliver health benefits to the target host as a potential probiotic drink, which can be confirmed through future in vivo studies.

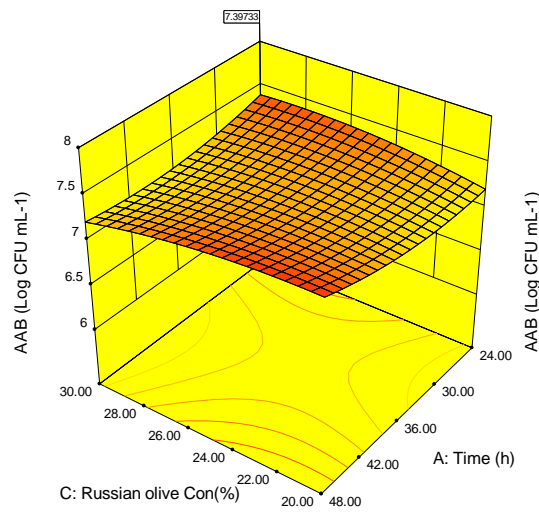

a

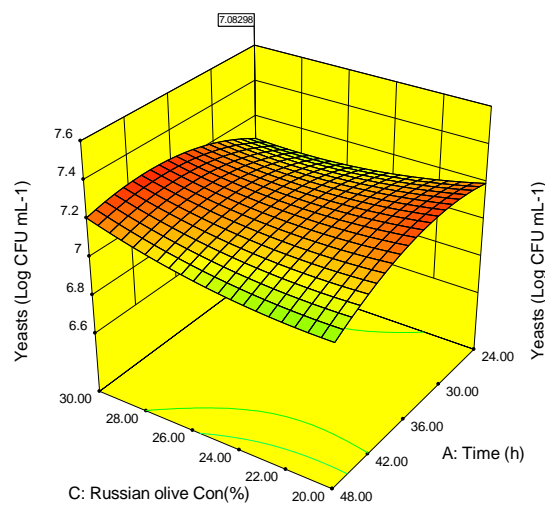

d

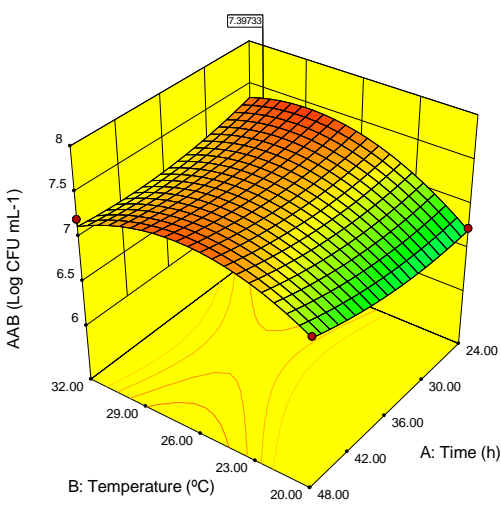

b

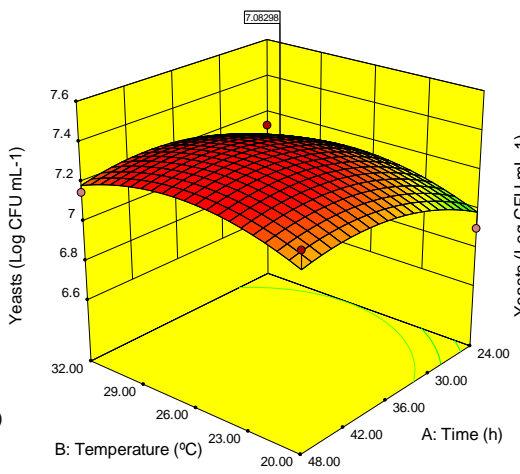

$\mathrm{e}$

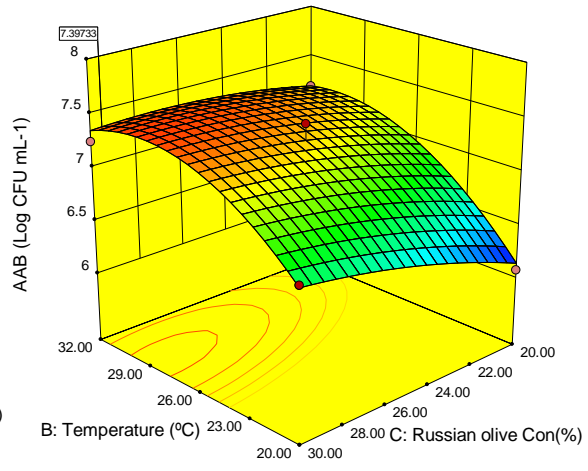

C

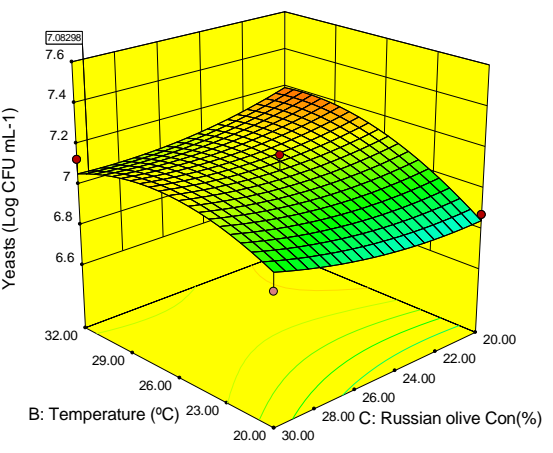

f 


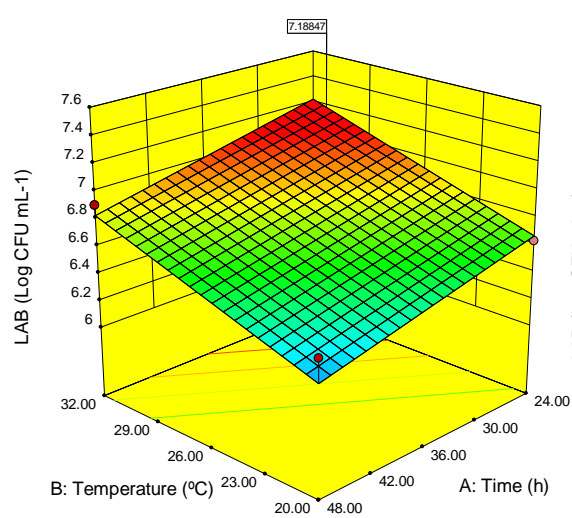

g

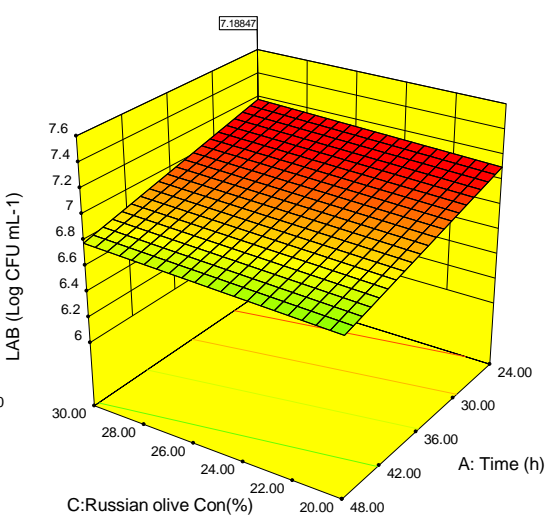

$\mathrm{h}$

Figure $23 D$ plots showing the combined effect of time, temperature and Russian olive juice concentration on the cell viability of Acetic acid bacteria $(A-C)$, yeasts $(D-F)$ and Lactic acid bacteria $(G-H)$.

\subsection{Model fitting}

Using a second-order polynomial equation, the independent and response variables were fitted to the experimental data. Table 2 presents the linear and quadratic equations, as well as the statistical significance for each response. As shown in Table 3, an insignificant P-value $(p>0.05)$ for lack of fit for all investigated variables indicates satisfactory accuracy of the six proposed mathematical models for estimation of the corresponding variable responses. The high coefficients of determination ( $\mathrm{R}^{2}$ values) of the linear and quadratic polynomial models indicate that the experimental data fit the equation effectively. In addition, to validate the model's accuracy, adj$\mathrm{R}^{2}$, and coefficient of variation (CV) were estimated. The low $\mathrm{CV}$ values $(0.67-15.35 \%)$ indicate high precision of the experiments, and adequate precision values greater than 4 (9.17-16.79) are desirable and imply reliability of the models with good signal to noise ratios. 
Table 2 Regression equation coefficients for the response of RWK fermented product response models.

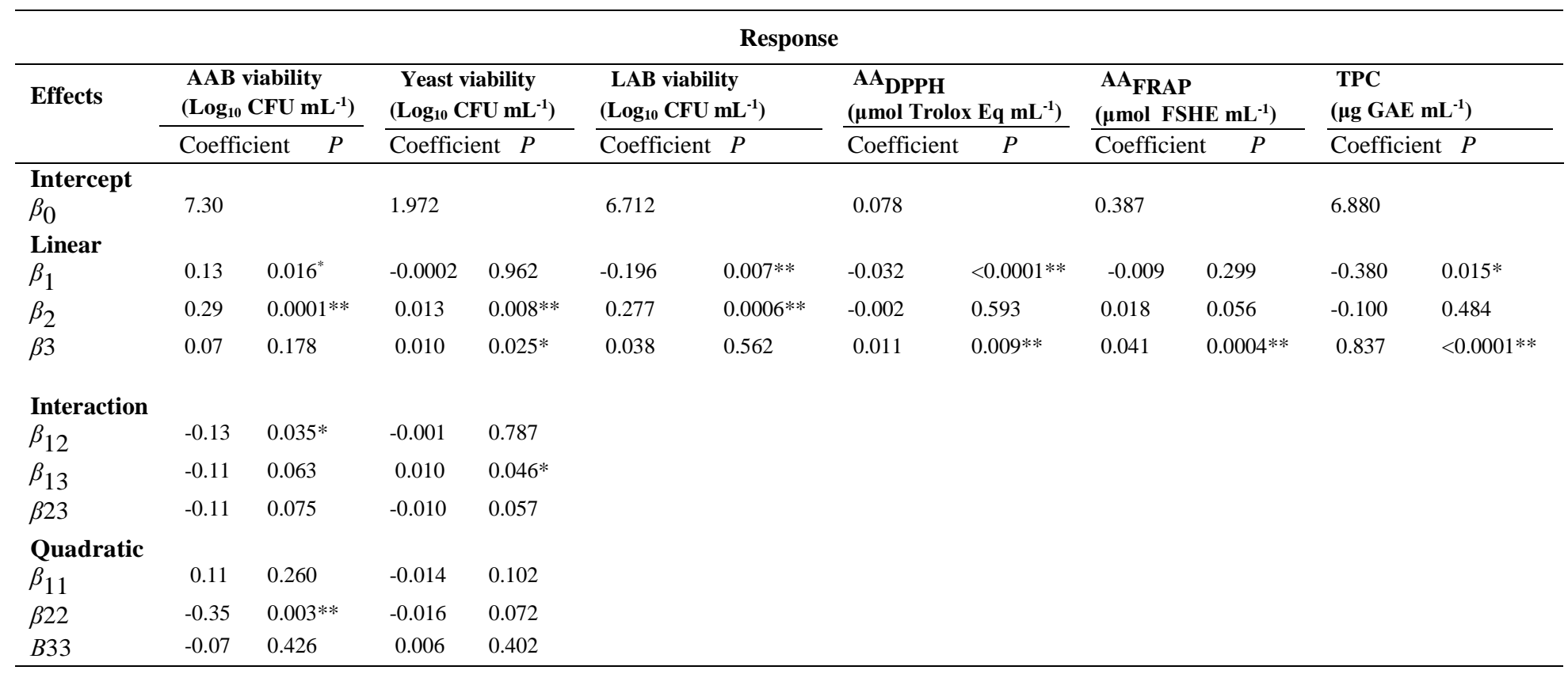

Effects are statistically significant $0.01 \leq P^{*}<0.05, P^{* *}<0.01$. The coefficients of the polynomial model include the constant term $\left(\beta_{0}\right)$, linear effects $\left(\beta_{1}, \beta_{2}, \beta_{3}\right)$, quadratic effects $\left(\beta_{11}, \beta_{22}, \beta_{33}\right)$ and interaction effects $\left(\beta_{12}, \beta_{13}\right.$ and $\left.\beta_{23}\right)$.

(RWK: Russian olive water kefir, CFU: Colony-forming unit, AAB: Acetic acid bacteria, LAB: Lactic acid bacteria, AADPPH: Antioxidant activity value using 1,1-diphenyl-2-picrylhydrazyl method, AAFRAP: Antioxidant activity value using ferric reducing antioxidant power test, FSHE: Ferrous sulfate heptahydrate equivalent, TPC: Total phenolic content, GAE: Gallic acid equivalent)

Table 3 Analysis of variance (ANOVA) for the response of Russian olive water kefir fermented products experimental variables.

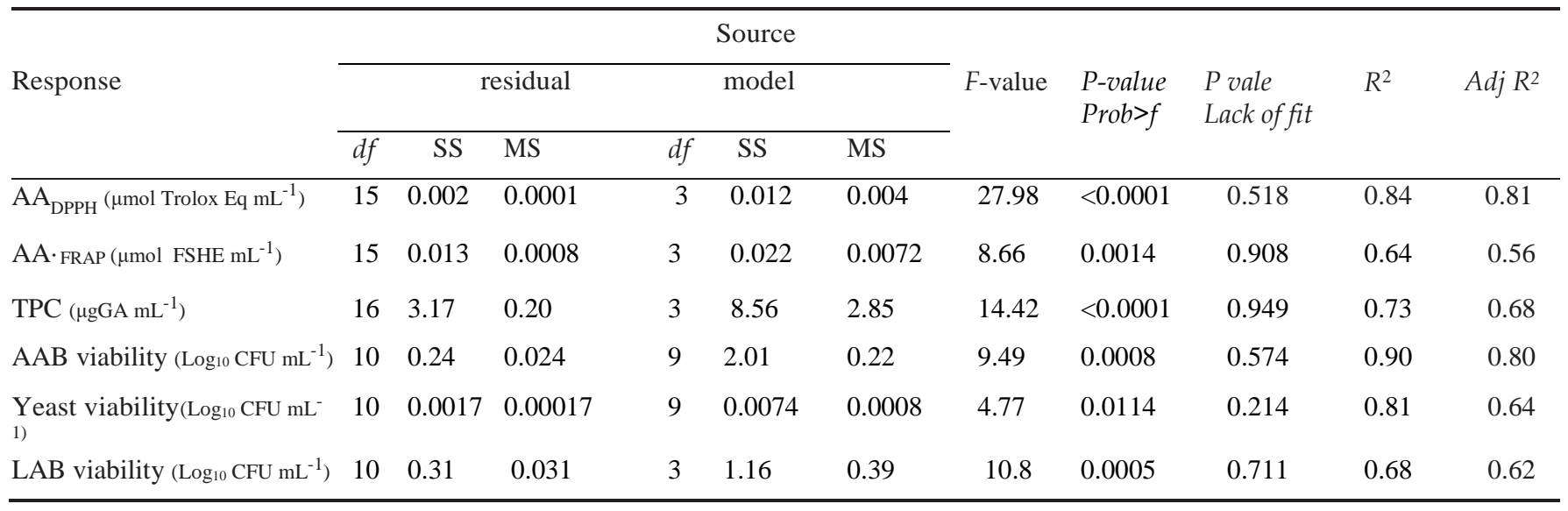

F-values imply the models are significant. These values indicate a significant $(p<0.05)$ relationship between independent and response variables and can be used to predict the corresponding responses of the RWK beverage 


\subsection{Process optimization}

Using the RSM response optimizer, the overall optimum region was determined to be at the temperature of $31.2^{\circ} \mathrm{C}$, fermentation time of 24 hours, and the $30 \%$ concentration of Russian olive. According to Figure 3, which presents the results of the optimization process, predicted response values under the optimum conditions for FRAP, DPPH radical scavenging, and TPC were 0.199 ( $\mu \mathrm{mol}$ FSHE/mL), 0.121 ( $\mu \mathrm{mol}$ Trolox Eq/mL), and $101.939(\mu \mathrm{g} \mathrm{GAE} / \mathrm{mL}$ ) respectively. Also, the predicted values for microbial viability (of AAB, LAB, and yeasts) were 7.39, 7.18, and $7.08 \log _{10}$ CFU/mL, respectively. Regression coefficients of the developed linear and quadratic models exhibited significant $(p<0.05)$ relationships between the dependent variables and corresponding responses of the final RWK product. The optimum value of 0.718 was selected for the desirability function.

\subsection{Verification of the models}

The models' validity was accomplished by conducting the water kefir fermentation process under optimal conditions determined by the models, at the temperature of $31.2^{\circ} \mathrm{C}$, fermentation time of 24 hours, and using the $30 \%$ concentration of Russian olive. The corresponding experimental values were compared with model-predicted response values (Table 4). The RMSE value, which is the square root of the residuals variance, indicates the absolute fit of the model to the data and illustrates how close the observed values for the optimized fermentation condition are to the model's predicted values. The low RSME values prove that the experimental model's predicted values are in good agreement with the experimental results. RSME values (ranging from 0.020.3.62) imply that the proposed model could accurately predict the responses in real experimental conditions. Finally, the physicochemical properties of the produced RWK, including pH, ethanol 
content, soluble solid content, and viscosity, were measured and reported as 4.1, 0.65 (\%), 9.7 $\left({ }^{\circ} \mathrm{Br}\right)$, and $1.52(\mathrm{cP})$, respectively.

Table 4 Predicted and experimental values of the responses at optimum conditions.

\begin{tabular}{llll}
\hline Predicated & Experimental & Response variable & Root Mean Square Error \\
\hline 101.939 & 98.32 & TPC $\quad(\mu \mathrm{g}$ GAE $/ \mathrm{mL})$ & 3.62 \\
0.121 & 0.096 & DPPH $(\mu \mathrm{mol}$ Trolox Eq/mL) & 0.03 \\
0.199 & 0.22 & FRAP $(\mu \mathrm{mol} \mathrm{FSHE} / \mathrm{mL})$ & 0.02 \\
7.39 & 7.20 & AAB viability $\left(\log _{10} \mathrm{CFU} / \mathrm{mL}\right)$ & 0.19 \\
7.18 & 7.06 & LAB viability $\left(\log _{10} \mathrm{CFU} / \mathrm{mL}\right)$ & 0.12 \\
7.08 & 7.17 & Yeast viability $\left(\log _{10} \mathrm{CFU} / \mathrm{mL}\right)$ & 0.09 \\
\hline
\end{tabular}

\section{Conclusion}

By using Russian olive in water kefir fermentation, a novel non-dairy (water kefir) beverage with enhanced bioactivities is developed. In addition, this is the first study where the fermentation process of RWK is optimized using advanced bioreactors and response surface methodology. The developed predictive models for all responses of interest of the water kefir yielded predictable and reproducible results, and the verification of the models showed a close agreement between the experimental values and the predicted values. RSM predicted that a set level of $30 \%$ Russian olive juice concentration over 24 hours of fermentation at the temperature of $31.2^{\circ} \mathrm{C}$ would provide the optimum conditions for preparing water kefir beverage with maximal TPC, antioxidant activity, and microbial viability of water kefir microorganisms. Under the optimum fermentation conditions, the values for FRAP, DPPH radical scavenging, and TPC in RWK were 0.22 ( $\mu$ mol FSHE/mL), 0.096 ( $\mu \mathrm{mol}$ Trolox Eq/mL) and $98.32(\mu \mathrm{g} \mathrm{GAE} / \mathrm{mL}$ ), and the microbial viability (of $\mathrm{AAB}, \mathrm{LAB}$, and yeasts) were 7.20, 7.06, and $7.17 \log 10 \mathrm{CFU} / \mathrm{mL}$, respectively. The optimized RWK process in this study can facilitate its production at a larger scale for satisfying a wider range of non-dairy consumers with limited availability of kefir-like products. 


\section{Acknowledgments}

The authors would like to thank Professor Mohammad Amin Mohammadifar, Dr. Clara Navarrete

Román, Jorien Hattink, and the technical staff in the DTU Fermentation core (Technical University

of Denmark) for their continued support. The authors also thank the Canadian Natural Sciences

and Engineering Research Council (NSERC) and the Graduate Mobility Award of McGill

University for their funding of this project, as well as the Fermentation Based Biomanufacturing

initiative funded by the Novo Nordisk Fonden (grant nr. NNF17SA0031362).

\section{Conflicts of interest}

The authors declare no conflict of interest.

\section{References}

Alsayadi, M., Al Jawfi, Y., Belarbi, M., \& Sabri, F. Z. (2013). Antioxidant potency of water kefir. The Journal of Microbiology, Biotechnology and Food Sciences, 2(6), 2444.

Alsayadi, M., Al Jawfi, Y., Belarbi, M., Soualem-Mami, Z., Merzouk, H., Sari, D. C., et al. (2014). Evaluation of anti-Hyperglycemic and anti-hyperlipidemic activities of water kefir as probiotic on Streptozotocin-induced diabetic Wistar rats. Journal of Diabetes Mellitus, $4(02), 85$.

AOAC (1990). Official Methods of Analysis (Vol. 1): Association of Official Analytical Chemists. AOAC (2000). Official methods of analysis. AOAC International Gaithersburg, MD.

Atalar, I., \& Dervisoglu, M. (2015). Optimization of spray drying process parameters for kefir powder using response surface methodology. LWT-Food Science and Technology, 60(2), 751-757.

Athanasiadis, I., Paraskevopoulou, A., Blekas, G., \& Kiosseoglou, V. (2004). Development of a novel whey beverage by fermentation with kefir granules. Effect of various treatments. Biotechnology Progress, 20(4), 1091-1095.

Ayed, L., Ben Abid, S., \& Hamdi, M. (2017). Development of a beverage from red grape juice fermented with the Kombucha consortium. [journal article]. Annals of Microbiology, 67(1), 111-121, doi:10.1007/s13213-016-1242-2.

Baú, T. R., Garcia, S., \& Ida, E. I. (2013). Optimization of a fermented soy product formulation with a kefir culture and fiber using a simplex-centroid mixture design. International Journal of Food Sciences and Nutrition, 64(8), 929-935, doi:10.3109/09637486.2013.816935.

Benzie, I. F., \& Strain, J. J. (1996). The ferric reducing ability of plasma (FRAP) as a measure of "antioxidant power": the FRAP assay. Analytical biochemistry, 239(1), 70-76.

Bertazzoni, E., Donelli, G., Midtvedt, T., Nicoli, J., \& Sanz, Y. (2013). Probiotics and clinical effects: is the number what counts? : Taylor \& Francis. 
Bitaraf, M. S., Khodaiyan, F., Mohammadifar, M. A., \& Mousavi, S. M. (2012). Application of Response Surface Methodology to Improve Fermentation Time and Rheological Properties of Probiotic Yogurt Containing Lactobacillus reuteri. Food and bioprocess technology, 5(4), 1394-1401, doi:10.1007/s11947-010-0433-2.

Brand-Williams, W., Cuvelier, M.-E., \& Berset, C. (1995). Use of a free radical method to evaluate antioxidant activity. LWT-Food Science and Technology, 28(1), 25-30.

CFIA (2019). Health claims on food labels. https://www.inspection.gc.ca/food-labelrequirements/labelling/industry/health-claims-on-food-

labels/eng/1392834838383/1392834887794?chap=10. Accessed May 2020.

Commission, C. A. (2018). Joint FAO/WHO Food Standards Programme. Codex Committee on Nutrition and Foods for Special Dietary Uses. Fortieth Session. Discussion paper on the scientific criteria for health related claims. Berlin, Germany: Codex Alimentarius Commission.

Corona, O., Randazzo, W., Miceli, A., Guarcello, R., Francesca, N., Erten, H., et al. (2016). Characterization of kefir-like beverages produced from vegetable juices. LWT-Food Science and Technology, 66, 572-581.

Cui, X.-H., Chen, S.-J., Wang, Y., \& Han, J.-R. (2013). Fermentation conditions of walnut milk beverage inoculated with kefir grains. LWT - Food Science and Technology, 50(1), 349352, doi:https://doi.org/10.1016/j.1wt.2012.07.043.

Diosma, G., Romanin, D. E., Rey-Burusco, M. F., Londero, A., \& Garrote, G. L. (2014). Yeasts from kefir grains: isolation, identification, and probiotic characterization. World Journal of Microbiology and Biotechnology, 30(1), 43-53.

Du, X., \& Myracle, A. (2018). Development and evaluation of kefir products made with aronia or elderberry juice: sensory and phytochemical characteristics. International Food Research Journal, 25(4).

Ekbatan, S. S., Sleno, L., Sabally, K., Khairallah, J., Azadi, B., Rodes, L., et al. (2016). Biotransformation of polyphenols in a dynamic multistage gastrointestinal model. Food Chemistry, 204, 453-462.

Farzaei, M. H., Bahramsoltani, R., Abbasabadi, Z., \& Rahimi, R. (2015). A comprehensive review on phytochemical and pharmacological aspects of Elaeagnus angustifolia L. Journal of Pharmacy and Pharmacology, 67(11), 1467-1480.

Fiorda, de Melo Pereira, G. V., Thomaz-Soccol, V., Rakshit, S. K., Pagnoncelli, M. G. B., Vandenberghe, L. P. d. S., et al. (2017). Microbiological, biochemical, and functional aspects of sugary kefir fermentation - A review. Food Microbiology, 66(Supplement C), 86-95, doi:https://doi.org/10.1016/j.fm.2017.04.004.

Fiorda, Pereira, G., Thomaz-Soccol, V., Medeiros, A. P., Rakshit, S. K., \& Soccol, C. R. (2016). Development of kefir-based probiotic beverages with DNA protection and antioxidant activities using soybean hydrolyzed extract, colostrum and honey. LWT - Food Science and Technology, 68(Supplement C), 690-697, doi:https://doi.org/10.1016/j.lwt.2016.01.003.

Fiorda, F., Pereira, G., Thomaz-Soccol, V., Medeiros, A. P., Rakshit, S. K., \& Soccol, C. R. (2016). Development of new potentialy probiotic honey beverage fermented by kefir grains= functional properties, molecular microbiological characteristics and technological aspects.

Fonteles, T. V., Costa, M. G. M., de Jesus, A. L. T., Fontes, C. P. M. L., Fernandes, F. A. N., \& Rodrigues, S. (2013). Stability and Quality Parameters of Probiotic Cantaloupe Melon Juice Produced with Sonicated Juice. Food and bioprocess technology, 6(10), 2860-2869, doi:10.1007/s11947-012-0962-y. 
Ghasemlou, M., Khodaiyan, F., \& Gharibzahedi, S. M. T. (2012). Enhanced Production of Iranian Kefir Grain Biomass by Optimization and Empirical Modeling of Fermentation Conditions Using Response Surface Methodology. Food and bioprocess technology, 5(8), 3230-3235, doi:10.1007/s11947-011-0575-x.

Gulitz (2013). Analysis of the diversity of water kefir microbiota by culture-dependent andindependent approaches. Universitätsbibliothek der TU München,

Gulitz, Stadie, J., Wenning, M., Ehrmann, M. A., \& Vogel, R. F. (2011). The microbial diversity of water kefir. International Journal of Food Microbiology, 151(3), 284-288, doi:10.1016/j.ijfoodmicro.2011.09.016.

Heim, K. E., Tagliaferro, A. R., \& Bobilya, D. J. (2002). Flavonoid antioxidants: chemistry, metabolism and structure-activity relationships. The Journal of nutritional biochemistry, 13(10), 572-584.

Hole, A. S., Rud, I., Grimmer, S., Sigl, S., Narvhus, J., \& Sahlstrøm, S. (2012). Improved bioavailability of dietary phenolic acids in whole grain barley and oat groat following fermentation with probiotic Lactobacillus acidophilus, Lactobacillus johnsonii, and Lactobacillus reuteri. Journal of agricultural and food chemistry, 60(25), 6369-6375.

Hsieh, H.-H., Wang, S.-Y., Chen, T.-L., Huang, Y.-L., \& Chen, M.-J. (2012). Effects of cow's and goat's milk as fermentation media on the microbial ecology of sugary kefir grains. Int $J$ Food Microbiol, 157(1), 73-81.

Hur, S. J., Lee, S. Y., Kim, Y.-C., Choi, I., \& Kim, G.-B. (2014). Effect of fermentation on the antioxidant activity in plant-based foods. Food Chemistry, 160, 346-356.

Huynh, N. T., Van Camp, J., Smagghe, G., \& Raes, K. (2014). Improved release and metabolism of flavonoids by steered fermentation processes: a review. International journal of molecular sciences, 15(11), 19369-19388, doi:10.3390/ijms151119369.

Incilay, G. (2014). Volatile Composition, Antimicrobial and Antioxidant Properties of Different Parts from Elaeagnus angustifolia L. Journal of Essential Oil Bearing Plants, 17(6), 1187 1202, doi:10.1080/0972060X.2014.929044.

ISO (1998). Microbiology of food and animal feeding stuffs-horizontal method for the enumeration of mesophilic lactic acid bacteria - colony-count technique at 30 degrees $\mathrm{C}$. ISO 15214: 1998. International Organization for Standardization Geneva.

Koh, W. Y., Utra, U., Rosma, A., Effarizah, M. E., Rosli, W. I. W., \& Park, Y.-H. (2017). Development of a novel fermented pumpkin-based beverage inoculated with water kefir grains: a response surface methodology approach. Food Science and Biotechnology, 1-11.

Laureys, D., \& De Vuyst, L. (2014). Water kefir as a promising low-sugar probiotic fermented beverage. Archives of Public Health, 72(S1), P1.

Łopusiewicz, Ł., Drozłowska, E., Siedlecka, P., Mężyńska, M., Bartkowiak, A., Sienkiewicz, M., et al. (2019). Development, characterization, and bioactivity of non-dairy kefir-like fermented beverage based on flaxseed oil cake. Foods, 8(11), 544.

M'hir, S., Rtibi, K., Mejri, A., Ziadi, M., Aloui, H., Hamdi, M., et al. (2019). Development of a Novel Whey Date Beverage Fermented with Kefir Grains Using Response Surface Methodology. Journal of Chemistry, 2019, 1218058, doi:10.1155/2019/1218058.

Magalhães, K. T., Pereira, G. V. M., Dias, D. R., \& Schwan, R. F. (2010). Microbial communities and chemical changes during fermentation of sugary Brazilian kefir. World Journal of Microbiology and Biotechnology, 33, 1-10. 
Marsh, A. J., O'Sullivan, O., Hill, C., Ross, R. P., \& Cotter, P. D. (2013). Sequence-based analysis of the microbial composition of water kefir from multiple sources. FEMS Microbiology Letters, 348(1), 79-85.

Martínez-Torres, A., Gutiérrez-Ambrocio, S., Heredia-del-Orbe, P., Villa-Tanaca, L., \& Hernández-Rodríguez, C. (2017). Inferring the role of microorganisms in water kefir fermentations. International Journal of Food Science \& Technology, 52(2), 559-571.

Melo, A., \& Silva, M. A. (2014). Development of fermented and flavoured kefir milk. BMC Proceedings, 8(4), P15, doi:10.1186/1753-6561-8-S4-P15.

Mishra, S., \& Mishra, H. N. (2015). Optimization of the prebiotic \& probiotic concentration and incubation temperature for the preparation of synbiotic soy yoghurt using response surface methodology. LWT - Food Science and Technology, 62(1, Part 2), 458-467, doi:https://doi.org/10.1016/j.lwt.2014.12.003.

Moore, J., Cheng, Z., Hao, J., Guo, G., Liu, J.-G., Lin, C., et al. (2007). Effects of solid-state yeast treatment on the antioxidant properties and protein and fiber compositions of common hard wheat bran. Journal of Agricultural and Food Chemistry, 55(25), 10173-10182.

Neve, H., \& Heller, K. (2002). The microflora of water kefir: a glance by scanning electron microscopy. Kieler Milchwirtschaftliche Forschungsberichte, 54(4), 337-349.

Nguyen, H. T. H., Ong, L., Lefèvre, C., Kentish, S. E., \& Gras, S. L. (2014). The Microstructure and Physicochemical Properties of Probiotic Buffalo Yoghurt During Fermentation and Storage: a Comparison with Bovine Yoghurt. Food and Bioprocess Technology, 7(4), 937953, doi:10.1007/s11947-013-1082-z.

Nindo, C. I., Tang, J., Powers, J. R., \& Singh, P. (2005). Viscosity of blueberry and raspberry juices for processing applications. Journal of Food Engineering, 69(3), 343-350, doi:https://doi.org/10.1016/j.jfoodeng.2004.08.025.

Pidoux, M. (1989). The microbial flora of sugary kefir grain (the gingerbeer plant): biosynthesis of the grain fromLactobacillus hilgardii producing a polysaccharide gel. [journal article]. MIRCEN Journal of Applied Microbiology and Biotechnology, 5(2), 223-238, doi:10.1007/bf01741847.

Pientaweeratch, S., Panapisal, V., \& Tansirikongkol, A. (2016). Antioxidant, anti-collagenase and anti-elastase activities of Phyllanthus emblica, Manilkara zapota and silymarin: an in vitro comparative study for anti-aging applications. Pharmaceutical Biology, 54(9), 1865-1872, doi:10.3109/13880209.2015.1133658.

Puerari, C., Magalhães, K. T., \& Schwan, R. F. (2012). New cocoa pulp-based kefir beverages: Microbiological, chemical composition and sensory analysis. Food Research International, 48(2), 634-640, doi:https://doi.org/10.1016/j.foodres.2012.06.005.

Randazzo, W., Corona, O., Guarcello, R., Francesca, N., Germana, M. A., Erten, H., et al. (2016). Development of new non-dairy beverages from Mediterranean fruit juices fermented with water kefir microorganisms. Food Microbiology, 54, 40-51.

Rodrigues, K. L., Araújo, T. H., Schneedorf, J. M., Ferreira, C. d. S., Moraes, G. d. O. I., Coimbra, R. S., et al. (2016). A novel beer fermented by kefir enhances anti-inflammatory and antiulcerogenic activities found isolated in its constituents. Journal of Functional Foods, 21(Supplement C), 58-69, doi:https://doi.org/10.1016/j.jff.2015.11.035.

Rodrigues, K. L., Caputo, L. R. G., Carvalho, J. C. T., Evangelista, J., \& Schneedorf, J. M. (2005). Antimicrobial and healing activity of kefir and kefiran extract. International Journal of Antimicrobial Agents, $25(5)$ 404-408, doi:https://doi.org/10.1016/j.ijantimicag.2004.09.020. 
Romero-Luna, H. E., Peredo-Lovillo, A., Hernández-Mendoza, A., Hernández-Sánchez, H., Cauich-Sánchez, P. I., Ribas-Aparicio, R. M., et al. (2020). Probiotic Potential of Lactobacillus paracasei CT12 Isolated from Water Kefir Grains (Tibicos). Current Microbiology.

Schneedorf, J. M. (2012). Kefir D'Aqua and Its Probiotic Properties, 53-76.

Septembre-Malaterre, A., Remize, F., \& Poucheret, P. (2018). Fruits and vegetables, as a source of nutritional compounds and phytochemicals: Changes in bioactive compounds during lactic fermentation. Food Research International, 104, 86-99, doi:https://doi.org/10.1016/j.foodres.2017.09.031.

Varga, Z., Pálvölgyi, M., Juhasz-Roman, M., \& Toth-Markus, M. (2006). Development of therapeutic kefir-like products with low galactose content for patients with galactose intolerance. Acta Alimentaria, 35(3), 295-304.

Wang, Y., Guo, T., Li, J. Y., Zhou, S. Z., Zhao, P., \& Fan, M. T. Four flavonoid glycosides from the pulps of Elaeagnus angustifolia and their antioxidant activities. In Advanced Materials Research, 2013 (Vol. 756, pp. 16-20): Trans Tech Publ

Zanirati, D. F., Abatemarco, M., Sandes, S. H. D. C., Nicoli, J. R., Nunes, T. C., \& Neumann, E. (2015). Selection of lactic acid bacteria from Brazilian kefir grains for potential use as starter or probiotic cultures. [Article]. Anaerobe, 32, 70-76, doi:10.1016/j.anaerobe.2014.12.007.

Zare, F., Boye, J. I., Champagne, C. P., Orsat, V., \& Simpson, B. K. (2013). Probiotic Milk Supplementation with Pea Flour: Microbial and Physical Properties. Food and Bioprocess Technology, 6(5), 1321-1331, doi:10.1007/s11947-012-0828-3. 